\title{
CLOSANTEL AS A POTENTIAL LIPOPOLYSACCHARIDE BIOSYNTHESIS INHIBITOR IN SHIGELLA SONNEI 4303
}

\section{LAURA DEUTSCH-NAGYa,b, ${ }^{a}$, PÉTER URBÁN ${ }^{b}$, HUNOR SZEBENI', BEÁTA ALBERT ${ }^{c}$, BÉLA KOCSIS ${ }^{\mathrm{d}}$, FERENC KILÁR ${ }^{\mathrm{a}, \mathrm{c},{ }^{*}}$}

\begin{abstract}
Shigella spp. are Gram-negative intracellular pathogenic bacteria belonging to the family Enterobacteriaceae. The pathophysiological impact of the bacteria is highly related to the composition and structural variability of lipopolysaccharides. Serum sensitivity and biofilm forming ability are correlated with the length of these molecules, while bacteria with truncated lipopolysaccharides are more sensitive to hydrophobic antibiotics. Inhibitors of lipopolysaccharide biosynthesis have the potential to develop new antimicrobial agents or antibiotic adjuvants. Bacterial two-component systems enable bacteria to sense and to respond to the changes in different environmental conditions. This study focuses on the inhibition of the $r f a D$ gene encoding the ADP-L-glycero-D-mannoheptose-6-epimerase, which is involved in the lipopolysaccharide biosynthesis. Although, there are some inhibitors presumed for bacterial two-component systems like Closantel, their impact on lipopolysaccharide biosynthesis has not been examined previously. The Shigella sonnei 4303 strain was involved in the experiments with known lipopolysaccharide structure. The effect of Closantel on lipopolysaccharide biosynthesis and the limitations of its use are presented.
\end{abstract}

Keywords: lipopolysaccharide, lipooligosaccharide, lipopolysaccharide biosynthesis, Closantel, Shigella sonnei

a Institute of Bioanalysis, Medical School, University of Pécs, Szigeti út 12., 7624 Pécs, Hungary

b Szentágothai Research Center, University of Pécs, Ifjúság útja 20., 7624 Pécs, Hungary

c Department of Bioengineering, Sapientia Hungarian University of Transylvania and Emergency County Hospital, Piața Libertății nr. 1., 530104 Miercurea Ciuc, Romania

d Department of Medical Microbiology and Immunology, Medical School, University of Pécs, Szigeti út 12, 7624 Pécs, Hungary

*Corresponding authors: nagylottii@gmail.com, ferenc.kilar@aok.pte.hu 
LAURA DEUTSCH-NAGY, PÉTER URBÁN, HUNOR SZEBENI, BEÁTA ALBERT, BÉLA KOCSIS, FERENC KILÁR

\section{INTRODUCTION}

Shigella sonnei is a Gram-negative, enteric pathogen, causing bacillary dysentery. Among all Shigella species, S. sonnei is the most prevalent one in developed countries [1]. With low infectious dose (as low as $10^{2}$ colonyforming units) Shigella species are highly contagious. Well-described structure and genetic background of the surface lipopolysaccharide (LPS) of S. sonnei 4303 (phase II bacteria) made this strain of $S$. sonnei to be perfect for biosynthesis investigations. S. sonnei 4303 was first isolated and described in Pécs, Hungary [2], when the phenomenon of phase variations was examined. This phase I/ rough $(R)$ strain was formed by spontaneous plasmid loss from the $S$. sonnei phase I smooth $(S)$ strain due to the instable nature of the virulence plasmid [3]. Several $R$-type isogenic derivatives were further generated from this S. sonnei 4303 strain to perform structural and biosynthetic analysis on their truncated lipopolysaccharides [4-8]. A detailed description of the genes responsible for lipopolysaccharide biosynthesis in S. sonnei 4303 has also been carried out [9].

Lipopolysaccharides, as important cell wall constituents of Gramnegative bacteria, play significant role in the intraspecies and host-bacteria interactions. LPS molecules comprise three chemical regions: a hydrophobic lipid A moiety anchored to the outer membrane, a hydrophilic core oligosaccharide, and a hydrophilic O-oligosaccharide extending outwards from the cell surface. While the lipid A part is associated with endotoxicity, the polysaccharide chain is responsible for O-specific immunogenicity. The number and size-variation of the repeating units in the polysaccharide parts on the surface are associated with pathogenic characteristics and antibiotic sensitivity of the strains.

The core oligosaccharide domain (attached directly to lipid A) contains sugars like L-glycero-D-manno-heptose and 3-deoxy-D-manno-oct-2-ulosonic acid (Kdo) and minor non-carbohydrate components. However, defects in the biosynthesis of lipid $A$ and Kdo are lethal for the bacteria, and the blockade in the heptose biosynthesis results in shorter lipopolysaccharides and an increasing antibiotic susceptibility [10, 11]. Heptoses are not present in mammalian cells, thus the inhibition of their biosynthetic pathway provides a selective target to design novel antimicrobial agents.

The biosynthesis of heptoses is quite universal across the different bacterial species. In S. sonnei, the pathway of heptose biosynthesis (Figure 1) starts with sedoheptulose-7-phosphate obtained from the reaction of fructose6-phosphate with ribose-5-phosphate catalyzed by transketolase (TktA). Sedoheptulose-7-phosphate is then converted into D-glycero-D-mannoheptose-7-phosphate by ketose-aldose-isomerase $(\mathrm{GmhA})$. This is followed by the anomeric phosphorylation with the bifunctional D- $\beta$-D-heptose 7-phosphate kinase (HIdE). The next step is the dephosphorylation at the C-7 position by 
the phosphatase GmhB. Then, the HIdE enzyme catalyzes an adenylyl transfer to the phosphate group at the C-1 position, which leads to ADP-D-glycero- $\beta$ $D$-manno-heptose. Lastly, an epimerase (RfaD) performs the inversion of the D-stereochemistry of the C-6 hydroxyl group creating the ADP-L-glycero- $\beta$ $D-m a n n o-h e p t o s e$, which will be incorporated into the lipopolysaccharides. While the ADP-D-glycero- $\beta$-D-manno-heptose might also be incorporated into lipopolysaccharides, disturbances in this biosynthesis pathway may lead to truncated lipopolysaccharides, and an increased sensitivity against heat and hydrophobic antibiotics [12,13].
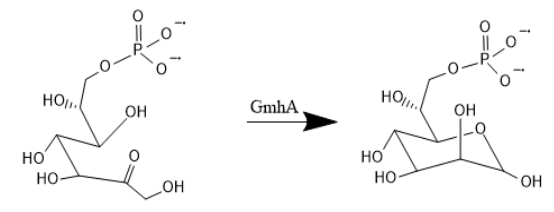

Sedoheptulose 7-phosphate

D-glycero-D-manno-heptose 7-phosphate
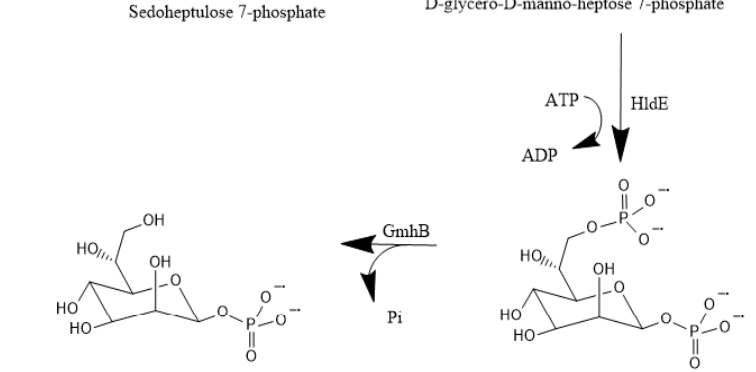

D-glycero-B-D-manno-heptose-1-phosphate

D-glycero-B-D-manno-heptose-1,7-bisphosphate
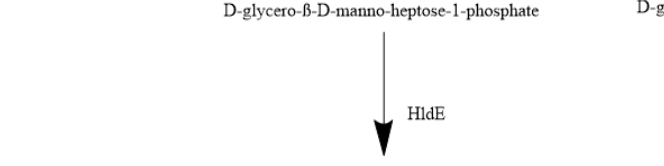

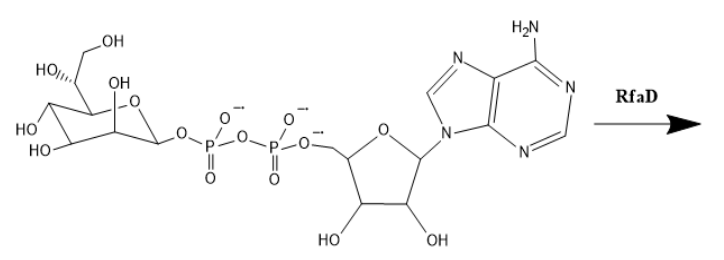

ADP-D-glycero-B-D-manno-heptose

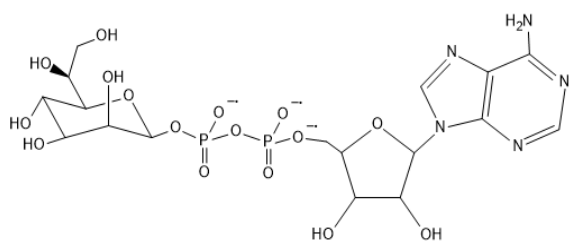

ADP-L-glycero-B-D-manno-heptose

Figure 1. The biosynthesis pathway of ADP-L-glycero- $\beta$-D-manno-heptose

Since LPSs are secondary gene products, the inhibition of the LPS biosynthesis may occur in two ways, either within the gene expression or by alteration in the enzyme activity. The connection between the LPS biosynthesis and the bacterial two-component system opens possibilities to influence the structure and integrity of LPSs. 
Closantel, a veterinary anthelmintic agent, is a potential histidine kinase $(\mathrm{HK})$ inhibitor with described effect on the bacterial two-component regulatory system $[14,15]$. However, the connection between Closantel and lipopolysaccharide biosynthesis has not yet been examined. Despite the low solubility of the molecule in aqueous solutions (16 mg/L), an active inhibitory effect was shown in in vitro experiments with different buffers. The potential influence of Closantel on rfaD expression was studied in this study.

\section{RESULTS AND DISCUSSION}

S. sonnei 4303 bacteria, having three L-glycero- $\beta$-D-manno-heptose molecular constituents in the core structure of their lipopolysaccharides, were grown in liquid medium in the absence and presence of Closantel. After culturing the cells, RNA was extracted, and cDNA was transcribed to perform qPCR analysis. In the experiments comparative analysis of the relative quantities can be performed by measuring the fluorescent signal. Figure 2 shows the fluorescent signal $(\Delta R n)$ of the amplification plotted against the cycles.

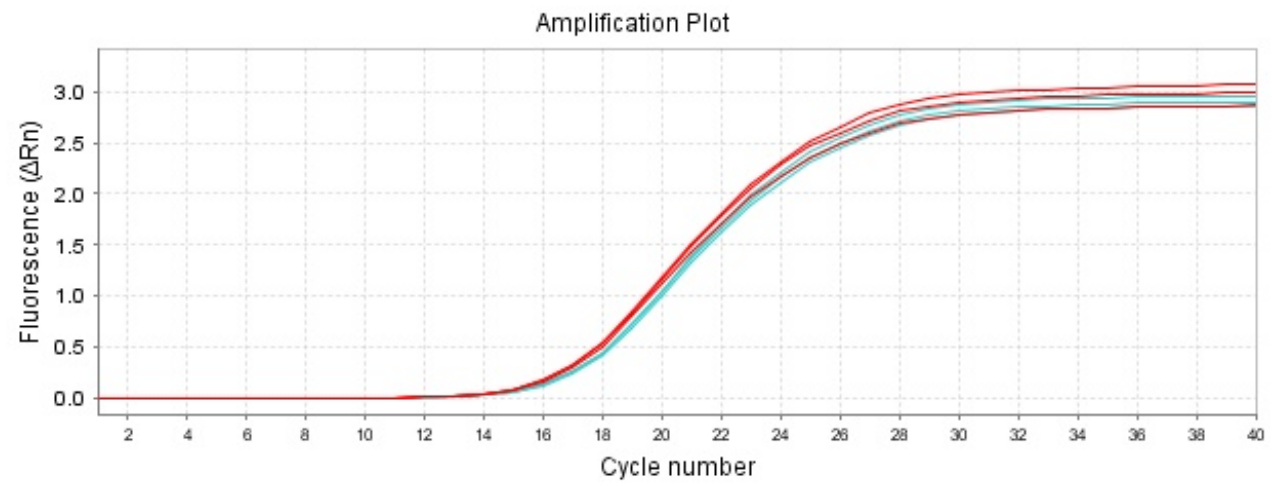

Figure 2. Amplification plot of the qPCR experiment showing the accumulation of the ifaD gene in Closantel treated (shown in blue) and in control (shown in red) Shigella sonnei 4303 samples. The $\Delta R n$ value is the difference between the normalized reporter value of the reaction and the baseline signal generated by the instrument.

A fluorescence level was selected at the exponential section of the amplification curves to mark a threshold. The cycle value where the curve reaches this fluorescence value is called threshold cycle $\left(\mathrm{C}_{\mathrm{T}}\right)$. The relative amount was compared with the Livak or the $\Delta \Delta \mathrm{C}_{\mathrm{T}}$ method, which take into account the changes in the control sample. First, the normalization of the 64 
$\mathrm{C}_{\mathrm{T}(\text { fraD })}$ level was made with the $\mathrm{C}_{\mathrm{T}(\text { uid } A)}$ level, and the $\Delta \mathrm{C}_{\mathrm{T}}$ was calculated for the treated and control samples, respectively. In the second step, the $\Delta \mathrm{C}_{\mathrm{T}}$ value of the control (untreated) sample was subtracted from the $\Delta \mathrm{C}_{\mathrm{T}}$ value of the treated sample. As last step, the expression ratio, or fold change difference was calculated. The amount of normalized $r f a D$ in the sample is described with a relative quantity $\left(R Q\right.$ value) where $R Q=2^{-\Delta \Delta C}$. The results are presented in Table 1.

Although, the absolute difference in the relative quantity values between the treated and untreated samples attained less than $R Q=1$, there is a mild difference (corresponding to $9.1 \%$ ) in the gene expression of $r f a D$ in S. sonnei 4303 cells treated with Closantel (Figure 3). Although, the difference in the relative fold change is low, it confirms that there is a detectable downregulation effect of this substance.

Table 1. Relative gene expression data and statistical values of $q P C R$ measurements of the $\mathrm{rfaD}$ and uidA genes in Shigella sonnei 4303 cultures treated with $16 \mathrm{mg} / \mathrm{L}$ Closantel and in untreated S. sonnei 4303 cells (control). Means were calculated from three replicates

\begin{tabular}{|c|c|c|c|c|c|c|}
\hline Sample & Target & $\mathrm{C}_{\text {T Mean }}$ & $\Delta \mathrm{C}_{\mathrm{T}}$ Mean & $\Delta \mathrm{C}_{\mathrm{T}} \mathrm{SE}$ & $\Delta \Delta \mathrm{C}_{\mathrm{T}}$ & $\mathrm{RQ}$ \\
\hline Control & $\mathrm{rfa} D$ & 17.48 & -0.24 & 0.04 & 0.00 & 1.00 \\
\hline Treated & $\mathrm{rfa} D$ & 17.87 & -0.11 & 0.03 & 0.14 & 0.91 \\
\hline
\end{tabular}

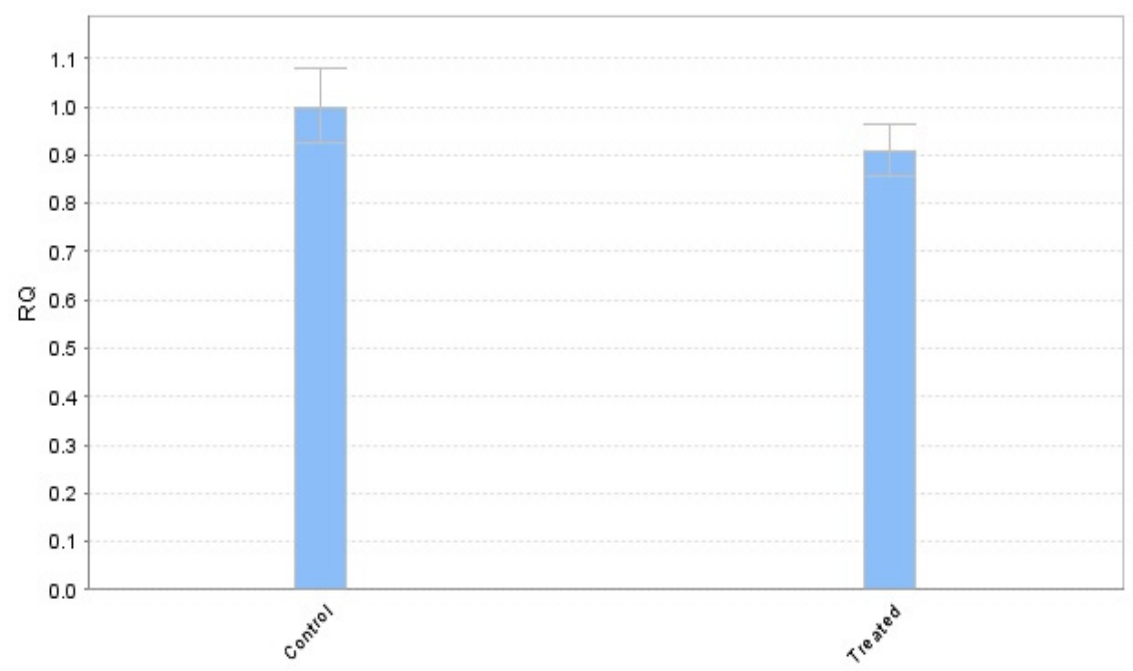

Sample

Figure 3. Box plot diagram of $R Q$ values: relative gene expression of $r f a D$ in treated and untreated Shigella sonnei 4303 cells 
The connection between the LPS biosynthesis and the bacterial twocomponent system have been examined earlier. LpxC inhibitors, known as potential active substances on the posttranscriptional level [16], or inhibitory components of heptose biosynthesis with proven effect studied by in vitro experiments have been described [17]. In parallel with enzyme inhibition, the silencing of different LPS biosynthesis genes has also been investigated. The downregulation of the $r f a D$ gene and its effect on LPS structure was described, e.g., in ntrC null mutant Vibrio vulnificus bacterium [18] (the ntrC is a regulatory protein of the bacterial two-component regulatory system), where the absence of the transcriptional activator $n t r C$ leads to the deficit of ADP-L-glycero-D-mannoheptose-6-epimerase as shown by comparative proteome analysis.

\section{CONCLUSIONS}

Relationship has been shown between the $r f a D$ gene and the bacterial two-component regulatory system, which leads to possibilities of influencing the biosynthesis of lipopolysaccharides. The search for $r f a D$ inhibitors is an important goal in successful medical treatment. Based on our results, it could be concluded that the presence of Closantel during cell growth has an effect on the expression of the $r f a D$ gene in $S$. sonnei bacterium. The mild connection between the presence of Closantel and the inhibition of LPS biosynthesis is, nevertheless, probably due to the low solubility of Closantel in aqueous media (i.e., in the broth medium for cell cultures). Therefore, further studies are needed applying different agents as possible two-component system inhibitors to investigate the endotoxin biosynthesis in Gram-negative bacteria.

\section{EXPERIMENTAL SECTION}

The experiments were performed with Shigella sonnei 4303 strain (S. sonnei 4303) with known lipopolysaccharide structure $[7,8]$ and genetic background [9]. Closantel in analytical standard grade (chemically $\mathrm{N}$ (5-chloro-4-((4-chlorophenyl)(cyano)methyl)-2-methylphenyl)-2-hydroxy-3,5diiodobenzamide) was purchased from Sigma-Aldrich (Saint Louis, Missouri, USA).

Bacteria were cultured for 36 hours in Luria-Bertani (LB) liquid medium in the presence of $16 \mathrm{mg} / \mathrm{L}$ of Closantel. This concentration value corresponds to the limit of solubility in LB liquid medium and this concentration is identical to the highest concentration used in pharmacokinetic examinations in animals [19]. 
Table 2 shows the TaqMan qPCR primers and probes (IDT, Coralville, lowa, USA) developed by using the gene sequences obtained from the National Center for Biotechnology Information database (https://www.ncbi.nlm.nih.gov). To normalize the differences in relative expression, uidA (beta-glucuronidase) gene was used as endogenous control.

Cells were disrupted with liquid nitrogen, and a NucleoSpin RNA kit (Macherey-Nagel, Düren, Germany) was used to extract total RNA from $2 \mathrm{~mL}$ of lysed cell culture. DNase, included in the kit, was used to degrade any remaining DNA. Complementary DNA (cDNA) library was created by the High-Capacity cDNA Reverse Transcription Kit (Thermo Fischer Scientific, Waltham, Massachusetts, USA).

Table 2. Primer and probe sequences used to amplify uid $A$ and $r f a D$ sequences

\begin{tabular}{|l|l|}
\hline \multicolumn{2}{|l|}{ uidA } \\
\hline Forward primer & GAATACGGCGTGGATACGTTAG (sense) \\
\hline Reverse primer & GATCAAAGACGCGGTGATACA (antisense) \\
\hline Probe & TGAAGAGTATCAGTGTGCATGGCTGG (sense) \\
\hline rfaD & CGTTGAACGTCTACGGTTACTC (sense) \\
\hline Forward primer & CCTTCACGCGGTCCATAAA (antisense) \\
\hline Reverse primer & TCGCAGATTGTTGGCTTCCGCTAT (sense) \\
\hline Probe &
\end{tabular}

After aqueous dilutions for equal concentrations, qPCR analyses were performed with the StepOne Plus (Thermo Fischer Scientific, Waltham, Massachusetts, USA), with the TaqMan Real-Time PCR Master Mix (Thermo Fischer Scientific, Waltham, Massachusetts, USA), and with TaqMan Mini Kit (IDT, Coralville, lowa, USA) to analyze the expression level of $r f a D$ in control (S. sonnei 4303 strains grown in the absence of Closantel) and treated cells. Measurements were performed in three biological replicates.

\section{ACKNOWLEDGEMENTS} 2017-19.

This work was supported by the grants NKFIH K-125275 and PTE-AOK-KA- 
LAURA DEUTSCH-NAGY, PÉTER URBÁN, HUNOR SZEBENI,

BEÁTA ALBERT, BÉLA KOCSIS, FERENC KILÁR

\section{REFERENCES}

1. C.N. Thompson; P.T. Duy; S. Baker; PLoS Negl Trop Dis, 2015, 9, e0003708.

2. K. Rauss; I. Kétyi; A. Vertényi; S. Vörös; Acta Microbiol Acad Sci Hung, 1961, 8, 53-63.

3. R. Schuch; A.T. Maurelli; Infect Immun, 1997, 65, 3686-3692.

4. B. Kocsis; T. Kontrohr; V. László; H. Milch; Acta Microbiol Acad Sci Hung, 1980, 27, 217.

5. T. Kontrohr; B. Kocsis; J Biol Chem 1981, 256, 7715-7718.

6. B. Kocsis; T. Kontrohr; J Biol Chem, 1984, 259, 11858-11860.

7. A. Bui; A. Kilár; A. Dörnyei; V. Poór, K. Kovács; B. Kocsis; F. Kilár; Croat Chem Acta, 2011, 84, 393-398

8. A. Kilár; A. Dörnyei; A. Bui, Z. Szabó, B. Kocsis, F. Kilár; J Mass Spectrom, 2011, 46, 61-70.

9. L. Deutsch-Nagy; P. Urbán; Z. Tóth; Z. Bihari; B. Kocsis; C. Fekete; F. Kilár; Gut Pathog, 2018, 10, 47.

10. M.A. Valvano; P. Messner; P. Kosma; Microbiology, 2002, 148, 1979-1989.

11. P.L. Taylor; K.M. Blakely; G.P. de Leon; J.R. Walker; F. McArthur; E. Evdokimova; K. Zhang; M.A. Valvano; G.D. Wright; M.S. Junop; J Biol Chem, 2008, 283, 28352845.

12. Karow; S. Raina; C. Georgopoulos; O. Fayet; Res. Microbiol, 1991, 142, 289-294

13. H. Osada; T. Beppu; Agric Biol Chem, 2014, 49:6, 1813-1819

14. D.J. Hlasta; J.P. Demers; B.D. Foleno; S.A. Fraga-Spano; J. Guan; J.J. Hilliard; M.J. Macielag; K.A. Ohemeng; C.M. Sheppard; Z. Sui; G.C. Webb; M.A. WeidnerWells; H. Werblood, J.F. Barrett; Bioorg Med Chem Lett., 1998, 8, 1923-1928.

15. K. Stephenson, Y. Yamaguchi, J.A. Hoch; J Biol Chem, 2000, 275, 38900-38904.

16. M.C. Pirrung; L.N. Tumey; C.R. Raetz; J.E. Jackman; K. Snehalatha; A.L. McClerren; C.A. Fierke; S.L. Gant;, K.M. Rusche; J Med Chem 2002, 45, 4359-4370.

17. G.P. De Leon; N.H. Elowe; K.P. Koteva; M.A. Valvano; G.D. Wright; Chem Biol, 2006, 13, 437-441.

18. H.S. Kim; M.A. Lee; S.J. Chun; S.J. Park; K.H. Lee; Mol Microbiol, 2007, 63, 559574.

19. M. Michiels, W. Meuldermans, J. Heykants; Drug Metab Rev, 1987, 18, 235-251. 